\title{
Audit of state-funded antiviral treatment for chronic hepatitis C in Qatar
}

A. K. John, ${ }^{1}$ S. Al Kaabi, ${ }^{7}$ A. John, ${ }^{2}$ R. Sing $h^{2}$ and M. Derbala ${ }^{7}$

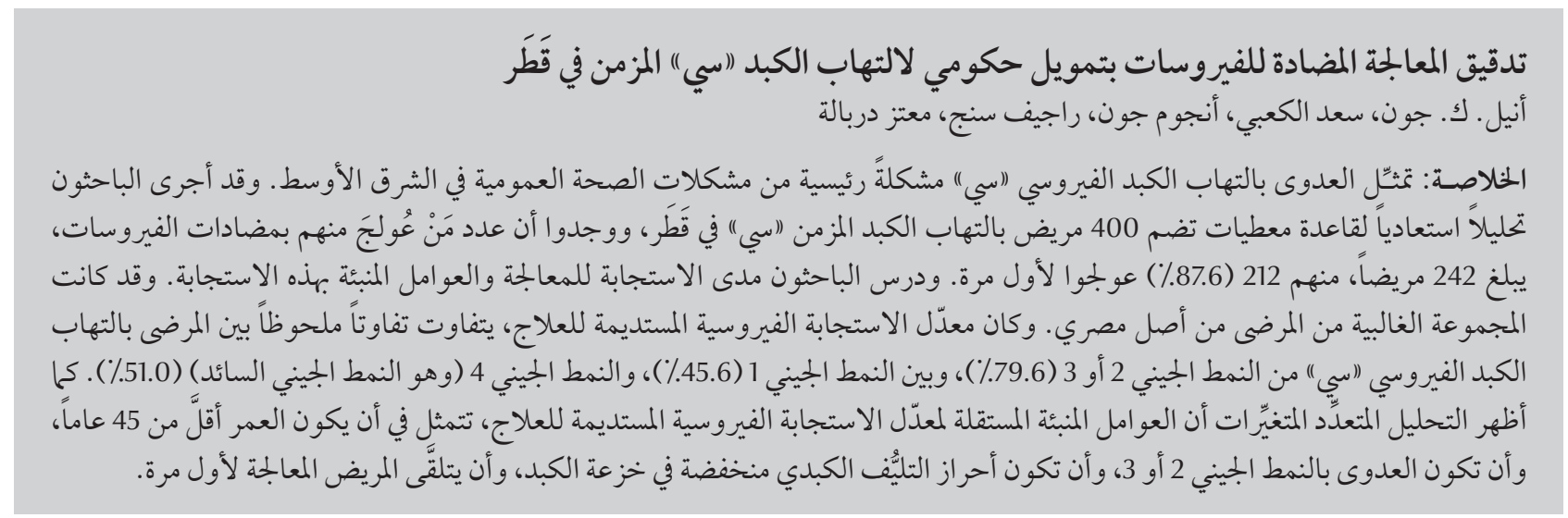

ABSTRACT Hepatitis C virus (HCV) infection is a major public health problem in the Middle East. A database of 400 patients with chronic HCV in Qatar was retrospectively analysed: 242 patients underwent antiviral treatment, of whom $212(87.6 \%)$ were naïve to treatment. The response to treatment and the predictors of response were studied. The largest group of patients were of Egyptian origin. The rate of sustained virological response (SVR) varied significantly between patients with HCV genotypes 2 or $3(79.6 \%)$ and genotype 1 (45.6\%) and 4 (the predominant genotype) (51.0\%). Multivariate analysis showed that the independent predictors of SVR were age $<45$ years, infection with genotypes 2 or 3, low fibrosis score on liver biopsy and naïve treatment status.

\section{Audit du traitement antirétroviral subventionné par l'État pour l'hépatite C chronique au Qatar}

RÉSUMÉ L'infection par le virus de l'hépatite C (VHC) est un problème de santé publique majeur au MoyenOrient. Une base de données de 400 patients souffrant d'hépatite C chronique au Qatar a fait l'objet d'une analyse rétrospective : 242 patients ont reçu un traitement antiviral, pour la première fois pour 212 d'entre eux $(87,6 \%)$. La réaction au traitement et les facteurs prédictifs de la réaction ont été étudiés. La majeure partie des patients était d'origine égyptienne. On a constaté une nette différence des taux de réponse virologique durable (RVD) entre les patients infectés par le VHC de génotypes 2 ou 3 (79,6 \%), de génotype 1 (45,6 \%) et de génotype 4 - le génotype prédominant - (51\%). L'analyse multivariée a révélé que les facteurs prédictifs indépendants de la RVD étaient un âge inférieur à 45 ans, une infection par les génotypes 2 ou 3, un faible taux de fibrose à la biopsie hépatique et le fait d'être naïf de traitement. 


\section{Introduction}

Chronic hepatitis $\mathrm{C}$ virus (HCV) infection is a major public health problem affecting more than 170 million people worldwide [1]. Around 20\% of these patients are at risk of developing cirrhosis and liver failure [2]. The prevalence of chronic $\mathrm{HCV}$ varies from $0.5 \%-1 \%$ in low-prevalence areas to over $20 \%$ in high-prevalence areas such as Egypt [1].

The Gulf state of Qatar attracts a large number of expatriate workers from neighbouring countries and South-East Asia, who are tested at entry to the country for $\mathrm{HCV}$ infection, as a part of the routine medical screening procedure. The state-owned medical facility provides subsidized treatment for $\mathrm{HCV}$ for expatriates and Qatar patients alike. This provision of subsidized treatment benefits mostly expatriate workers and has provided us with a large database of chronic HCV patients of different nationalities and diverse genotypes. This large pool of data was used to study the epidemiological characteristics and response to therapy from a genotype perspective. This study further aimed to determine the predictors of sustained virological response (SVR) to treatment with pegylated interferon (PegIFN) and ribavirin.

\section{Methods}

A retrospective study was conducted from the files of patients referred to the hepatitis clinic of our tertiary care stateowned medical facility. The research and ethics committee of the institution approved the study and a waiver of informed consent was obtained from the Institutional Review Board.

A total of 400 consecutive patients referred with positive hepatitis $\mathrm{C}$ serology over a period of 2 years starting from September 2004 were studied using a purposive non-probability sampling technique. Patients were categorized according to $\mathrm{HCV}$ genotype. The following patient data was collected: age, sex, nationality, body mass index (BMI) and risk factors for HCV transmission. The risk factors enquired about were history of: blood transfusion or use of blood products, parenteral treatment for schistosomiasis, intravenous drug abuse, major surgery, prolonged hospitalization or haemodialysis. The laboratory data collected included routine haematology, biochemistry including liver function tests and coagulation profile, fibrosis score on liver biopsy, viral load by quantitative polymerase chain reaction (PCR) and HCV genotype. Treatment details, side-effect profile and treatment compliance for each patient was also collected.

The patients had been treated with either Peg-IFN alpha 2a $180 \mu \mathrm{g} /$ week (Pegasys, Hoffmann-La Roche) or Peg-IFN alpha 2b (Pegintron, Schering Plough) $1.5 \mu \mathrm{g} / \mathrm{kg} /$ week, plus weightadjusted ribavirin daily. Patients infected with $\mathrm{HCV}$ genotypes 1 and 4 were treated for 48 weeks with ribavirin 1000 mg daily in patients with weight of $\leq 75$ $\mathrm{kg}$ or ribavirin $1200 \mathrm{mg}$ daily if weight > $75 \mathrm{~kg}$, while patients infected with HCV genotypes 2 or 3 were treated for 24 weeks with ribavirin $800 \mathrm{mg}$ daily and Peg-IFN, as per American Association for the Study of Liver Diseases guidelines [3].

Serological testing for HCV antibody was done by enzyme-linked immunosorbent assay (ELISA) (Ortho-Clinical Diagnostics). Serum HCV RNA was detected by reverse transcriptase polymerase chain reaction (RT-PCR-Amplicor Molecular System, Hoffmann-La-Roche) and HCV genotyping was carried out using a line probe assay (Inno-LiPA HCV II, Immunogenetics). Liver biopsy grading and staging was done using the system of Scheuer et al. [4]. Patients with quantitative HCV-RNA with liver biopsy evidence of chronic hepatitis (stage F1 or more) were considered for treatment. Patients with decompensated cirrhosis, pre-existing autoimmune disorders, known psychiatric disorders or focal lesions on abdominal imaging suggestive of hepatocellular carcinoma or elevated $\alpha$-fetoprotein were excluded from treatment.

\section{Assessment of safety}

During treatment, patients were assessed as outpatients with a clinical examination and complete blood count to detect the occurrence of serious adverse effects. Liver function tests - serum alanine aminotransferase (ALT) and aspartate aminotransferase (AST) were done at 2 -week intervals in the first month and then every 4 weeks up to the end of the treatment. Patients were also monitored on the above schedule for adverse events and medication compliance. During treatment, thyroid function and creatinine levels were checked every 12 weeks.

For adverse events related to PegIFN, the dose was decreased by $50 \%$ temporarily and for ribavirin related side-effects the dose of ribavirin was lowered to $600 \mathrm{mg}$ per day. Full doses could be restarted after the disappearance of side-effects. In the event of adverse events persisting despite support with growth factors, the drug was discontinued. Dose modification was considered when the haemoglobin $(\mathrm{Hb})$ level dropped to $<10 \mathrm{~g} / \mathrm{dL}$, neutrophils $<0.75 \times 10^{3} / \mathrm{mL}$ or platelets $<80 \times$ $10^{3} / \mathrm{mL}$, while drugs were discontinued completely for any patient showing $\mathrm{Hb}<8.5 \mathrm{~g} / \mathrm{mL}$, neutrophils $<0.5 \times$ $10^{3} / \mathrm{mL}$ (despite temporary support with growth factors), platelets $<50 \times$ $10^{3} / \mathrm{mL}$ and abnormal thyroid function.

\section{Assessment of efficacy}

The measures of efficacy were: end-oftreatment virological response (ETR), which was defined as undetectable HCV-RNA levels by qualitative PCR at the end of treatment; and SVR, defined as absentHCV-RNA byqualitativePCR 24 weeks after completing treatment. We did not include early virological response (EVR) - absence of HCVRNA after the end of the treatment - as 
an outcome measure. EVR was used only as a tool to discontinue expensive treatment for non-responders. Treatment was discontinued for genotypes 1 and 4 patients, if they did not achieve at least a 2-log reduction in viral load, i.e. EVR by 12 weeks of therapy. Patients who attained ETR but who became HCV-RNA positive at the end of 24 weeks after completion of treatment were classified as relapsers and those who were found to be HCV-RNA positive at the end of treatment were classified as non-responders. Those patients who had failed to clear the virus after a full course of standard IFN and were retreated with the combination therapy of Peg-IFN and ribavirin were included in the retreatment group.

\section{Analysis}

Data were expressed as mean and standard deviation (SD) unless otherwise stated. Student $t$-test was used to study the significance of difference between mean values of continuous variables. Comparisons were done by the chisquared test for categorical data and 1-wayanalysis ofvariance for quantitative data to determine significant differences between group means. $P \leq 0.05$ was considered statistically significant. Factors affecting SVR on univariate analysis were entered in a stepwise multiple logistic regression analysis. Odds ratios (OR) and $95 \%$ confidence intervals (CI) were estimated from the model. Data were analysed with SPSS, version 16.

\section{Results}

\section{Baseline data}

The demographic, clinical, biochemical, epidemiological, histological and virological features of the 400 patients studied, classified according to their genotypes are presented in Table 1. As we had only 2 patients with genotype 2 and genotypes 2 and 3 patients typically have a similar duration of treatment and similar response to treatment these groups were combined for analysis.

The patient population was multiethnic and multi-national. The patients were mostly from Egypt, the Middle East (native Qataris) and South-East Asia (Pakistanis).

There were 258 patients $(64.5 \%)$ who reported 1 or more known risk factors for HCV transmission (treatment for schistosomiasis, blood transfusion or family member positive for $\mathrm{HCV}$ ).

Genotype 4 was the predominant genotype seen in this centre $(64.0 \%)$ and $203 / 256(79.3 \%)$ of the genotype 4 patients were of Egyptian origin. The majority of genotype 3 patients $(70.1 \%)$

\begin{tabular}{|c|c|c|c|c|c|c|c|}
\hline \multirow{2}{*}{$\begin{array}{l}\text { Variable } \\
\text { Age [mean (SD) years] }\end{array}$} & \multicolumn{2}{|c|}{$\begin{array}{c}\text { Genotype } 1 \\
(n=79)(19.8 \%)\end{array}$} & \multicolumn{2}{|c|}{$\begin{array}{c}\text { Genotype } 4 \\
(n=256)(64.0 \%)\end{array}$} & \multicolumn{2}{|c|}{$\begin{array}{l}\text { Genotypes } 2 / 3 \\
(n=65)(16.3 \%)\end{array}$} & \multirow{2}{*}{$\begin{array}{r}P \text {-value } \\
0.51\end{array}$} \\
\hline & 44.9 & (10.3) & 47.5 & (9.9) & 46.2 & (11.0) & \\
\hline Sex, male (no., \%) & 58 & 73.4 & 213 & 83.2 & 45 & 76.9 & 0.03 \\
\hline BMI [mean (SD) $\left.\mathrm{kg} / \mathrm{m}^{2}\right]$ & 28.5 & (4.8) & 29.3 & (4.4) & 29.0 & (6.1) & 0.59 \\
\hline $\begin{array}{l}\text { Risk factors present } \\
\text { (no.\%) }\end{array}$ & 59 & 74.7 & 164 & 64.1 & 35 & 53.8 & 0.06 \\
\hline $\begin{array}{l}\text { High fibrosis score }(F 3, F 4) \\
\text { (no. \%) }\end{array}$ & $26 / 66$ & 39.3 & $74 / 233$ & 31.8 & $20 / 56$ & 36.4 & 0.68 \\
\hline$A L T^{b}($ no. \%) & & & & & & & 0.69 \\
\hline Normal & 19 & 24.1 & 53 & 20.7 & 16 & 24.6 & \\
\hline Near normal & 29 & 36.7 & 94 & 36.7 & 19 & 29.2 & \\
\hline Abnormal & 31 & 39.2 & 109 & 42.6 & 30 & 46.2 & \\
\hline \multicolumn{8}{|c|}{ Pretreatment viral load ${ }^{c}($ no. \%) } \\
\hline Low & 43 & 54.4 & $173^{d}$ & 67.6 & 37 & 56.9 & 0.001 \\
\hline High & 36 & 45.6 & 81 & 31.6 & 28 & 43.1 & \\
\hline \multicolumn{8}{|c|}{$\begin{array}{l}\text { Geographic origin of infection } \\
\text { (no.\%) }\end{array}$} \\
\hline Middle East & 41 & 51.9 & 31 & 12.1 & 15 & 23.1 & 0.001 \\
\hline Egypt & 28 & 35.4 & 131 & 81.2 & 2 & 3.1 & \\
\hline South-East Asia & 7 & 8.9 & 14 & 5.5 & 46 & 3.8 & \\
\hline Other & 3 & 3.8 & 6 & 2.3 & 24 & 36.9 & \\
\hline
\end{tabular}

${ }^{a}$ At least 1 known risk factor for transmission of infection identified.

${ }^{b}$ Normal $<40 \mathrm{IU} / \mathrm{mL}$; near normal 41-80 IU/mL; abnormal $>80 \mathrm{IU} / \mathrm{mL}$.

cHigh viral load $>700 \times 10^{3} \mathrm{IU} / \mathrm{mL}$; low viral load $\leq 700 \times 10^{3} \mathrm{IU} / \mathrm{mL}$.

${ }^{d}$ Data missing for 2 patients.

$B M I=$ body mass index $; S D=$ standard deviation; $A L T=$ alanine aminotransferase 
were from South-East Asia, mainly Pakistan.

Only 242 patients $(60.5 \%)$ were evaluated for treatment outcome: 171 (42.8\%) who had completed the combination treatment and 71 (17.8\%) who had discontinued treatment. The reasons for discontinuation of treatment were: absent EVR and discontinuation advised by the physician (45 patients); discontinuation advised by the physician due to side-effects (9 patients); or patient discontinued treatment on their own, without reporting any reason (17 patients). Of the rest, 133 (33.3\%) were either on treatment or awaiting treatment after full workup when we analysed the data and had to be excluded from the audit of treatment outcomes. Another 25 patients $(6.3 \%)$ developed contraindications for treatment and thus could not be started on antiviral treatment.

Of the 242 patients, who were evaluated for treatment outcomes, 212 were naive to treatment and the remaining 30 patients were nonresponders to previous treatment with standard interferon and ribavirin and hence they were subjected to retreatment with Peg-IFN and ribavirin.

\section{Virological response to treatment}

Table 2 shows the baseline patient characteristics in the Peg-IFN-treated group according to genotype and treatment outcome. None of the patient characteristics we studied-age, sex, mean ALT, ALT quotient (ALT/40, i.e. average of pretreatment ALT values before treatment, divided by the upper limit of normal), fibrosis score, pretreatment viral load, albumin, platelets, type of IFN used and treatment statuswere significantly different across the genotypes.

The ETR was significantly better $(P<$ 0.002) in patients with HCV genotypes
2/3 (84.7\%) than genotypes 1 (47.8\%) and 4 (59.3\%). Similarity, SVR was significantly better for genotypes $2 / 3$ (79.1\%) than genotypes 1 and 4 (45.6\% and $51.0 \%)(P<0.002)($ Table 2$)$.

\section{Predictors of treatment response}

We looked at many patient factors such as age, sex, ethnic background, fibrosis score [low (F1-F2) versus high (F3-F4)], ALT level, BMI, treatment response and genotype as predictors of response to treatment. Factors which were significant in the univariate analysis - age, fibrosis score, genotype and treatment status (Table 3) - were included in logistic regression analysis using the multivariate model. Age $<45$ years, low fibrosis score (F1-F2), genotypes $2 / 3$ and naive treatment status were significant predictors of SVR in the final model.

\begin{tabular}{|c|c|c|c|c|c|c|c|}
\hline \multirow{2}{*}{$\begin{array}{l}\text { Pretreatment variable } \\
\text { Age [mean }(S D) \text { years] }\end{array}$} & \multicolumn{2}{|c|}{$\begin{array}{l}\text { Genotype } 1 \\
(n=46)\end{array}$} & \multicolumn{2}{|c|}{$\begin{array}{l}\text { Genotype } 4 \\
(n=150)\end{array}$} & \multicolumn{2}{|c|}{$\begin{array}{l}\text { Genotypes } 2 / 3 \\
\quad(n=46)\end{array}$} & \multirow{2}{*}{$\begin{array}{c}P \text {-value } \\
\\
0.73\end{array}$} \\
\hline & 45.9 & $(9.1)$ & 46.5 & (8.4) & 45.3 & $(10.8)$ & \\
\hline Sex (male) (no. \%) & 35 & 76.1 & 129 & 86.0 & 32 & 69.6 & 0.05 \\
\hline BMI (no. \%) & & & & & & & 0.36 \\
\hline Normal & 17 & 18.1 & 43 & 45.7 & 34 & 36.2 & \\
\hline Overweight/obese & 29 & 19.6 & 75 & 50.7 & 44 & 29.7 & \\
\hline \multicolumn{8}{|l|}{ Laboratory parameters } \\
\hline High fibrosis score (F3,F4) (no. \% ) & $17 / 38$ & 44.7 & $51 / 137$ & 37.2 & $10 / 39$ & 25.6 & 0.11 \\
\hline ALT level [mean (SD] (IU/mL) & 83.2 & $(67.0)$ & 100.0 & $(82.2)$ & 98.3 & $(81.8)$ & 1.00 \\
\hline ALT quotient ${ }^{\mathrm{a}}[$ mean (SD)] & 2.1 & (1.7) & 2.5 & (1.6) & 2.4 & $(2.7)$ & 0.98 \\
\hline Albumin level [mean (SD)] (g/L) & 41.6 & $(4.1)$ & 42.0 & $(2.4)$ & 42.7 & (9.4) & 0.49 \\
\hline Platelet count [mean (SD)] $(\times 109 / \mathrm{L})$ & 212.1 & $(94.4)$ & 186.7 & $(62.0)$ & 212.1 & $(79.7)$ & 0.77 \\
\hline $\begin{array}{l}\text { Pretreatment viral load [mean (SD)] } \\
(\times 103 \mathrm{IU} / \mathrm{mL})\end{array}$ & 475.1 & $(201.2)$ & 437.4 & $(213.5)$ & 526.1 & $(200.7)$ & 0.95 \\
\hline \multicolumn{8}{|l|}{ Treatment } \\
\hline Naïve to treatment (no. \%) & 39 & 84.8 & 132 & 88.0 & 41 & 89.1 & 0.27 \\
\hline Peg-IFN $\alpha$-2a treatment (no. \%) & 38 & 82.6 & 135 & 90.0 & 40 & 87.0 & 0.14 \\
\hline \multicolumn{8}{|l|}{ Outcome (no. \%) } \\
\hline $\begin{array}{l}\text { End-of-treatment virological } \\
\text { response }\end{array}$ & $22 / 46$ & 47.8 & $89 / 150$ & 59.3 & $39 / 46$ & 84.7 & 0.002 \\
\hline Sustained virological response & $21 / 46$ & 45.6 & $75 / 147$ & 51.0 & $34 / 43$ & 79.1 & 0.002 \\
\hline
\end{tabular}

${ }^{a} A L T / 40$, i.e. the upper limit of normal.

$B M I=$ body mass index; $S D=$ standard deviation; $A L T=$ alanine aminotransferase. Peg-IFN a-2a = pegylated interferon alpha $2 a$. 


\begin{tabular}{|c|c|c|c|c|}
\hline \multirow[t]{2}{*}{ Variable } & \multicolumn{2}{|c|}{ Univariate analysis } & \multicolumn{2}{|c|}{ Multivariate analysis } \\
\hline & SVR (\%) & $P$-value & OR $(95 \% \mathrm{CI})^{\mathrm{a}}$ & $P$-value \\
\hline \multicolumn{5}{|l|}{ Age (years) } \\
\hline$\leq 45$ & 75.6 & & 1 & \\
\hline$>45$ & 51.7 & 0.001 & $0.3(0.14-0.62)$ & 0.001 \\
\hline \multicolumn{5}{|l|}{ Sex } \\
\hline Male & 62.2 & & & \\
\hline Female & 60.5 & 0.85 & - & 0.77 \\
\hline \multicolumn{5}{|l|}{ Ethnicity } \\
\hline Middle East & 63.4 & & & \\
\hline Egypt & 57.6 & & & \\
\hline SE Asia & 80.6 & & & \\
\hline Europe/America & 37.5 & 0.04 & - & 0.67 \\
\hline \multicolumn{5}{|l|}{$B M I$} \\
\hline Normal & 75.6 & & & \\
\hline Overweight/obese & 59.9 & 0.11 & - & 0.25 \\
\hline \multicolumn{5}{|l|}{ Fibrosis score } \\
\hline Low & 69.8 & & 1 & \\
\hline High & 49.3 & 0.01 & $0.47(0.23-0.97)$ & 0.04 \\
\hline \multicolumn{5}{|l|}{ ALT level } \\
\hline Normal/near normal & 60.0 & & & \\
\hline$>$ twice normal & 64.9 & 0.47 & - & 0.56 \\
\hline \multicolumn{5}{|l|}{ Pretreatment viral load } \\
\hline Low & 62.7 & & & \\
\hline High & 60.0 & 0.76 & - & 0.47 \\
\hline \multicolumn{5}{|l|}{ Naïve to treatment } \\
\hline Naïve & 65.9 & & 1 & \\
\hline Retreatment & 35.7 & 0.01 & $0.23(0.08-0.65)$ & 0.01 \\
\hline \multicolumn{5}{|l|}{ HCV genotype } \\
\hline 1 & 45.6 & & 1 & \\
\hline 4 & 51.0 & & $1.24(0.46-3.37)$ & 0.67 \\
\hline $2 / 3$ & 79.1 & 0.003 & $5.87(1.50-22.9)$ & 0.01 \\
\hline
\end{tabular}

${ }^{a}$ Only statistically significant data are reported.

$O R=$ odds ratio; $C I=$ confidence interval.

$B M I=$ body mass index $; S D=$ standard deviation; $A L T=$ alanine aminotransferase .

Only 11 of the 30 patients (36.6\%) who were retreated with Peg-IFN and ribavirin after of treatment with standard interferon had achieved SVR.

\section{Adverse effects}

\section{Haematological side-effects}

The haematological adverse effects were typical of those with Peg-IFN and ribavirin treatment. Neutropoenia requiring dose modification was seen in 41 (16.9\%) patients and 5 of these patients required support with growth factors to avoid significant dose reduction. Mild neutropoenia not requiring any dose modification was seen in another 72 patients (29.8\%) in the initial weeks of treatment, which later stabilized without further deterioration. Thrombocytopoenia was reported in 35 patients, who required dose modification. Anaemia was seen in 32 patients, who required reduction in the dose of ribavirin. Three (3) patients discontinued treatment due to their $\mathrm{Hb}$ dropping below $8 \mathrm{~g} /$ dL.

\section{Psychiatric side-effects}

Depression and suicidal ideation were reported in 6 patients. Severe depression with suicidal tendencies requiring stoppage of treatment was found in 3 patients.

\section{Thyroid side-effects}

Biochemical thyroid dysfunction was found in 12 patients, which required 
temporary suspension of Peg-IFN therapy and correction of the thyroid profile with appropriate intervention. One patient discontinued treatment due to persistent thyroid abnormalities.

\section{Dermatological side-effects}

Skin related side-effects were noted in 3 patients and severe skin reactions necessitating stoppage of therapy was seen in 1 patient.

\section{Autoimmune side effects}

One patient developed severe IFNinduced polymyositis with significant muscle weakness requiring stoppage of treatment and institution of steroid therapy [5].

\section{Discussion}

Our demographic data shows a predominance of genotype 4 patients. These patients were mainly from the large pool of Egyptian expatriates in our patient population, who form a major workforce in Qatar; 203/256 (79.3\%) of the genotype 4 patients were of Egyptian origin. This is the major genotype seen among Egyptians [6]. Almost two-thirds of our patients reported some known risk factors for $\mathrm{HCV}$ transmission, such as treatment for schistosomiasis [7], blood transfusion or another family member being known to be positive for HCV. Intrafamilial transmission has been reported as a possible route of transmission in Egypt [8]. Among our patients with genotype 3, 70.1\% were expatriates from Pakistan. The predominance of genotype 3 infection in South-East Asia is well documented [9].

Of the 242 patients who could be evaluated for response to therapy, 171 completed the entire course of prescribed antiviral treatment. As per the guidelines in our centre, 45 patients with absent EVR at 12 weeks had their treatment discontinued, since their chance of obtaining SVR was very remote [10].

Several host and viral factors have been reported to affect the response to Peg-IFN therapy [11]. Younger age was a significant factor in predicting response in our study and this is similar to the experience from other studies [12]. We found that age $<45$ years was associated with SVR in both univariate and multivariate analysis. We did not find that BMI affected SVR. However, there are reports of obesity being a negative predictor of response [13]. At the same time, there are studies which do not support the relationship between BMI and SVR [14].

Ethnicity has been reported as a factor predicting SVR $[15,16]$. In the univariate analysis we found that patients of South-East Asian origin had a significantly better response but this was not confirmed in the multivariate model. The predominance of genotype 3 , which is an easy-to-treat genotype among South-East Asians, might have confounded the results here. High fibrosis score on liver biopsy has been shown to be a negative predictor of response [17]. We found that a fibrosis score greater than F2 was a predictor of poor response in both the univariate and multivariate analyses.

The ETR and SVR rates were significantly better in the patients infected with HCV genotypes $2 / 3$ in comparison with genotypes 1 and 4 . Genotypes $2 / 3$ were also found to be significant predictors of favourable response to treatment in both the univariate and multivariate analyses. Genotype 1 was a significant predictor of poor response in several studies [18]. Reports from South-East Asia where genotype 3 is the dominant genotype have shown an SVR of over $80 \%$ [19]. We had similar SVR rates among our genotype 3 patients. Genotype 4 is known to be a difficult genotype to treat [20] and the SVR we obtained was similar to the SVR rates in genotype 1.

Patientswhounderwentretreatment for relapse or non-response to previous treatment with standard interferon had a poor SVR; retreatment was also a significant predictor of suboptimal SVR. SVR rates among patients who undergo retreatment have been reported to be $23 \%$ in non-responders and $41 \%$ ing relapsers [21]. The overall SVR rate in our retreated patients was $35.7 \%$.

In short, we conclude that in our large volume of clinical experience, variables such as sex, ethnicity, baseline ALT levels, BMI and viral load did not predict SVR. In contrast, factors such as young age, low fibrosis score on liver biopsy, naive treatment status and, most significantly, infection with HCV genotypes 2 or 3 were associated with SVR.

The retrospective design of our study notwithstanding, we believe that the findings of our study will assist clinicians in prognosis prior to embarking on prolonged and expensive antiviral treatment for chronic HCV.

\section{Acknowledgements}

We especially acknowledge the kind contributions of Dr Rafie Yakoob, Dr Nazeeh Dweik, Dr Fuad Pasic, Dr M.T. Butt, Dr Muneera Al Muhannadi and Dr Manik Sharma in the conduct of this study.

\section{References}

1. Abdel-Aziz F et al. Hepatitis C virus (HCV) infection in a community in the Nile Delta: population description and HCV prevalence. Hepatology, 2000, 32(1):111-115.

2. Sarbah SA, Younossi ZM. Hepatitis C: an update on the silent epidemic. Journal of Clinical Gastroenterology, 2000, 31(1):79.
3. Strader DB, Seef LB. AASLD guidelines. Diagnosis, management and treatment of hepatitis C. Hepatology, 2004, 39(4):1147-1157.

4. Scheuer PJ, Standish RA, Dhillon AP. Scoring of chronic hepatitis. Clinics in Liver Disease, 2002, 6(2):335-347, v-vi. 
5. John A et al. Polymyositis during pegylated alpha-interferon ribavirin therapy for chronic hepatitis. Indian Journal of Gastroenterology, 2007, 26(3):147-148.

6. Ray SC et al. Genetic epidemiology of hepatitis C virus throughout Egypt. Journal of Infectious Diseases, 2000, 182(3):698707.

7. Kamal et al. Clinical, virological and histopathological features: long-term follow-up in patients with chronic hepatitis C co-infected with S. mansoni. Liver, 2000, 20(4):281-289.

8. Mohamed MK et al. Intrafamilial transmission of hepatitis $\mathrm{C}$ in Egypt. Hepatology, 2005, 42(3):683-687.

9. Amarapurkar DN, Choksi M. Genotype III-HCV infection. Tropical gastroenterology, 2007, 28(2):58-63.

10. Fried MW et al. Peginterferon alfa-2a plus ribavirin for chronic hepatitis C virus infection. New England Journal of Medicine, 2002, 347(13):975-982.

11. Hu KQ, Vierling JM, Redeker AG. Viral, host and interferonrelated factors modulating the effect of interferon therapy for hepatitis C virus infection. Journal of Viral Hepatitis, 2001, 8(1):1-18.

12. Elefsiniotis IS et al. Patient's age modifies the impact of the proposed predictors of sustained virological response in chronic hepatitis $C$ patients treated with PEG-interferon plus ribavirin. European Journal of Internal Medicine, 2008, 19(4):266-270.

13. Bressler BL et al. High body mass index is an independent risk factor for nonresponse to antiviral treatment in chronic hepatitis C. Hepatology, 2003, 38(3):639-644.
14. Hu KQ et al. Clinical implications of hepatic steatosis in patients with chronic hepatitis C: a multicenter study of U.S. veterans. Digestive Diseases and Sciences, 2007, 52(2):570578.

15. Missiha $\mathrm{S}$ et al. Impact of Asian race on response to combination therapy with peginterferon alfa-2a and ribavirin in chronic hepatitis C. American Journal of Gastroenterology, 2007, 102(10):2181-2188.

16. Roulot D et al. Epidemiological characteristics and response to peginterferon plus ribavirin treatment of hepatitis $\mathrm{C}$ virus genotype 4 infection. Journal of Viral Hepatitis, 2007, 14(7):460-467.

17. Gad RR et al. Predictors of a sustained virological response in patients with genotype 4 chronic hepatitis C. Liver International, 2008, 28(8):1112-1119.

18. Simmonds $P$. Clinical relevance of hepatitis $C$ virus genotypes. Gut, 1997, 40(3):291-293.

19. Amarapurkar DN et al. Do different hepatitis $C$ virus genotypes behave differently? Tropical Gastroenterology, 2007, 28(3):99-104.

20. Derbala M et al. Pegylated interferon-alpha 2b-ribavirin combination in Egyptian patients with genotype 4 chronic hepatitis. Journal of Viral Hepatitis, 2005, 12(4):380-385.

21. Sherman $M$ et al. Peginterferon alfa-2a (40KD) plus ribavirin in chronic hepatitis $\mathrm{C}$ patients who failed previous interferon therapy. Gut, 2006, 55(11):1631-1638.

\section{Hepatitis C treatment}

The rationales for treatment of chronic hepatitis are to reduce inflammation, to prevent progression to fibrosis, cirrhosis and hepatocellular carcinoma through the eradication of the virus in chronically infected patients, and to decrease infectivity and control the spread of the disease.

Combination therapy results in better treatment responses than monotherapy; the highest response rates have been achieved with pegylated interferon in combination with ribavirin. The sooner in the evolution of the infection the treatment is started, the better the chances of responding to interferon-a therapy. The treatment strategy to be adopted depends on availability of drugs and cost and patient adherence is critical to the success of hepatitis $\mathrm{C}$ treatment.

Source: Hepatitis C

(http://www.who.int/csr/disease/hepatitis/whocdscsrlyo2003/en/index.html) 